\title{
Peri-prosthetic trans-patellar fractures after Total knee Arthroplasty: a case series and review of literature
}

\author{
Gaurav Govil ${ }^{1,2^{*}}$ (D), Lavindra Tomar ${ }^{1,3}$ and Pawan Dhawan ${ }^{1,4}$
}

\begin{abstract}
Peri-prosthetic patella fracture is the second most common peri-prosthetic fracture after total knee arthroplasty. This report presented the treatment results in 6 patients with peri-prosthetic patella fractures. From January 2015 to February 2019, six patients with peri-prosthetic patella fractures were treated. The mean age at surgery was 64 years (range, 48-72 years). Four patients with displaced fractures were treated surgically, and two patients with non-displaced fractures were treated non-surgically. Outcomes were assessed in terms of motion, functional knee score, and Knee Society score. The mean follow-up period lasted 16 months (range: 12-20 months). The average arc of motion was $110^{\circ}$ (range: $80^{\circ}-130^{\circ}$ ). The mean functional knee score was 77 (range: $70-87$ ). The mean Knee Society score was 84 (range: 75-89). The non-surgical treatment may be a good choice for non-displaced peri-prosthetic patella fractures. For displaced fractures, surgical treatments yielded good functional outcomes.
\end{abstract}

Level of evidence: IVa

Keywords: Peri-prosthetic patella fracture, Patella, Osteosynthesis, Complication, Trans-patellar fracture

\section{Introduction}

Peri-prosthetic patella fracture (PPPF) represents the second most common peri-prosthetic fracture after total knee arthroplasty (TKA). The reported prevalence rates stood somewhere between $0.2-21 \%$ in resurfaced patellae and was about $0.5 \%$ in un-resurfaced patellae [1-5]. Most PPPFs occur within 2 years after arthroplasty. Treatments include non-surgical and surgical methods, depending on the features of fractures $[2,4]$.

Currently, there is no universally-accepted validated classification system for PPPFs. The Ortiguera and Berry classification is most commonly used. It takes into account both stability of patellar implant and the extensor mechanism [6]. Goldberg et al [7] also developed a classification on the basis of extensor apparatus continuity and stability of patella resurfacing. However, this classification does not consider variability of fracture configuration and

\footnotetext{
* Correspondence: gauravgovil@yahoo.co.in

'Department of orthopaedics, Max Super Speciality Hospital, 108 A, I.P. Extension, Patparganj, Delhi 110092, India

${ }^{2}$ D-101, Sunshine Helios, Sector 78, Noida, Uttar Pradesh 201305, India Full list of author information is available at the end of the article
}

involvement of quadriceps tendon. Trans-patellar fractures with stable implant and intact extensor mechanism can be treated non-surgically [8]. On the other hand, displaced trans-patellar fractures require open reduction and internal fixation [5]. Patellar fractures with unstable implant require a revision arthroplasty.

This report introduced the treatments of PPPFs, with a review of the literature conducted.

\section{Patients and methods}

Informed consent was obtained from each patient before treatments. From January 2015 to February 2019, six patients with PPPFs were treated in our hospital, including two males and four females. The mean age at surgery was 64 years (range, $48-72$ years). The trans-patellar fractures occurred, on average, 14 months (range: 2 to 24 months) after TKA. Against the Ortiguera and Berry classification, 3 were of type I and 3 type II. Combined rheumatoid arthritis was found in one patient, and combined osteoarthritis was found in the other five patients. Post-traumatic PPPFs occurred in four knees, and atraumatic PPPFs were found in two knees. Four patients had pain. The PPPFs occurred

(c) The Author(s). 2020 Open Access This article is licensed under a Creative Commons Attribution 4.0 International License, which permits use, sharing, adaptation, distribution and reproduction in any medium or format, as long as you give appropriate credit to the original author(s) and the source, provide a link to the Creative Commons licence, and indicate if changes were made. The images or other third party material in this article are included in the article's Creative Commons licence, unless indicated otherwise in a credit line to the material. If material is not included in the article's Creative Commons licence and your intended use is not permitted by statutory regulation or exceeds the permitted use, you will need to obtain permission directly from the copyright holder. To view a copy of this licence, visit http://creativecommons.org/licenses/by/4.0/. 
Table 1 Details of 6 patients with peri-prosthetic patella fractures

\begin{tabular}{|c|c|c|c|c|c|c|c|c|c|c|}
\hline Case & $\begin{array}{l}\text { Age } \\
\text { (year) }\end{array}$ & Sex & Side & Implant & Cause & Association & Surface & TFITT (month) & ${ }^{\text {a } T y p e ~}$ & Treatment \\
\hline 1 & 68 & $\mathrm{~F}$ & L & $\begin{array}{l}\text { Rotating platform } \\
\text { PS knee }\end{array}$ & Fall & $\mathrm{OA}$ & $\operatorname{Re}$ & 2 & $\|$ & ORIF- CW + SE \\
\hline 2 & 65 & $\mathrm{~F}$ & L & PFC Sigma & Fall & $\mathrm{OA}$ & NRe & 23 & $\|$ & ORIF- SE + bracing \\
\hline 3 & 72 & $\mathrm{~F}$ & $\mathrm{R}$ & $\begin{array}{l}\text { PFC Sigma + } \\
\text { tibial stem }\end{array}$ & RRC & $\mathrm{OA}$ & NRe & 8 & I & $\mathrm{ORIF}-\mathrm{TBW}+\mathrm{SE}$ \\
\hline 4 & 64 & $\mathrm{~F}$ & L & PFC Sigma & RTA & $\mathrm{OA}$ & NRe & 24 & I & Cast \\
\hline 5 & 48 & M & L & PFC Sigma & No trauma & RA & $\operatorname{Re}$ & 15 & I & Cast \\
\hline 6 & 69 & M & $\mathrm{R}$ & PFC Sigma & No trauma & $\mathrm{OA}$ & NRe & 12 & $\|$ & $\mathrm{ORIF}-\mathrm{TBW}+\mathrm{SE}$ \\
\hline Mean & 64 & & & & & & & 14 & & \\
\hline
\end{tabular}

RA Rheumatoid arthritis, OA Osteoarthritits, Re Resurfaced patella, NRe Non-resurfaced patella, RRC Rising from a chair, TFITT Time from injuries to treatments; ${ }^{a}$ Ortiguera and Berry classification; ORIF Open reduction and internal fixation, CW Cerclage wiring, TBW Tension band wiring, SE Suturing with Ethibond

on the left knee $(n=4)$ and right knee $(n=2)$ (Table 1$)$. The index TKA was performed through the medial parapatellar incision. The prostheses included cemented posterior stabilized press-fit condylar implants (Sigma, DePuy Orthopaedics Inc., IN, USA) $(n=4)$ and implants with a tibial stem extender and a high-flexion rotating platform (Sigma, DePuy Orthopaedics Inc., IN, USA) $(n=2)$. There were two resurfaced patellae and four non-resurfaced patellae. We used a three-peg oval polyethylene patella for resurfacing. All treatments were performed by the same senior surgeon (LT). Two type I PPPFs were treated non-surgically, and the remaining four PPPFs (one type I and three type II) were treated surgically. After surgery, early mobilization with brace or plaster support was used whenever possible. The operated knees were immobilized for 4 weeks, and non-operated knees for 6 weeks. Range of motion exercise was started thereafter. Progressive knee flexion was advised based on the radiological evidence of fracture healing and clinical assessment of quadriceps muscle strength. Three months after treatment, patients were allowed to walk without walking aids.

Outcome assessments covered anterior knee pain, extensor lag, arc of motion, and functional ability (Excellent: arc of motion $>110^{\circ}$, extension lag $<5^{\circ}$, no pain; Good: arc of motion $=80^{\circ}-110^{\circ}$, extension lag $=5-10^{\circ}$, mild pain; Fair and Poor: arc of motion $<80^{\circ}$, extension lag $>10^{\circ}$, severe pain) [5]. The knees were also assessed in terms of Knee Society score.

\section{Results}

There was no reoperation. None of the patients developed infection, deep vein thrombosis, or pulmonary embolism. The mean follow-up period lasted 16 months (range: 12-20 months) (Table 1). The average arc of motion was $110^{\circ}$ (range: $80^{\circ}-130^{\circ}$ ). The functional knee score was 77 (range: 70-87). The mean Knee Society score was 84 (range: 75-89) (Table 2). The findings of pre- and postoperative X-ray examination of implants are presented in Figs. 1, 2, 3, 4.

\section{Discussion}

\section{Epidemiology}

PPPFs usually occur postoperatively and intraoperatively [9]. We conducted a comprehensive systematic review till 2006, and found that the majority of PPPFs was of type III (55\%), followed by type I (25\%) and type II (20\%) [10]. In our series, traumatic events accounted for $2 / 3$ of PPPFs, and two PPPFs were asymptomatic. The female-to-male ratio was reverse probably because increasing TKA was performed in elderly female patients who had a combined osteoporosis.

Table 2 Outcomes after one year

\begin{tabular}{lllllll}
\hline Case & $\begin{array}{l}\text { Follow-up } \\
\text { (month) }\end{array}$ & $\begin{array}{l}\text { AOM } \\
\left.\mathbf{(}^{\circ}\right)\end{array}$ & $\begin{array}{l}\text { Extensor lag } \\
\left(\mathbf{(}^{\circ}\right.\end{array}$ & Outcome & KSS & Functional score \\
\hline 1 & 18 & 110 & 10 & Good & 84 & 75 \\
2 & 15 & 100 & 10 & Fair & 83 & 70 \\
3 & 18 & 80 & 20 & Poor & 75 & 70 \\
4 & 20 & 130 & 0 & Excellent & 89 & 87 \\
5 & 12 & 120 & 5 & Excellent & 89 & 86 \\
6 & 15 & 110 & 10 & Good & 86 & 76 \\
Mean & 16 & 108 & 9 & & 84 & 77 \\
\hline
\end{tabular}




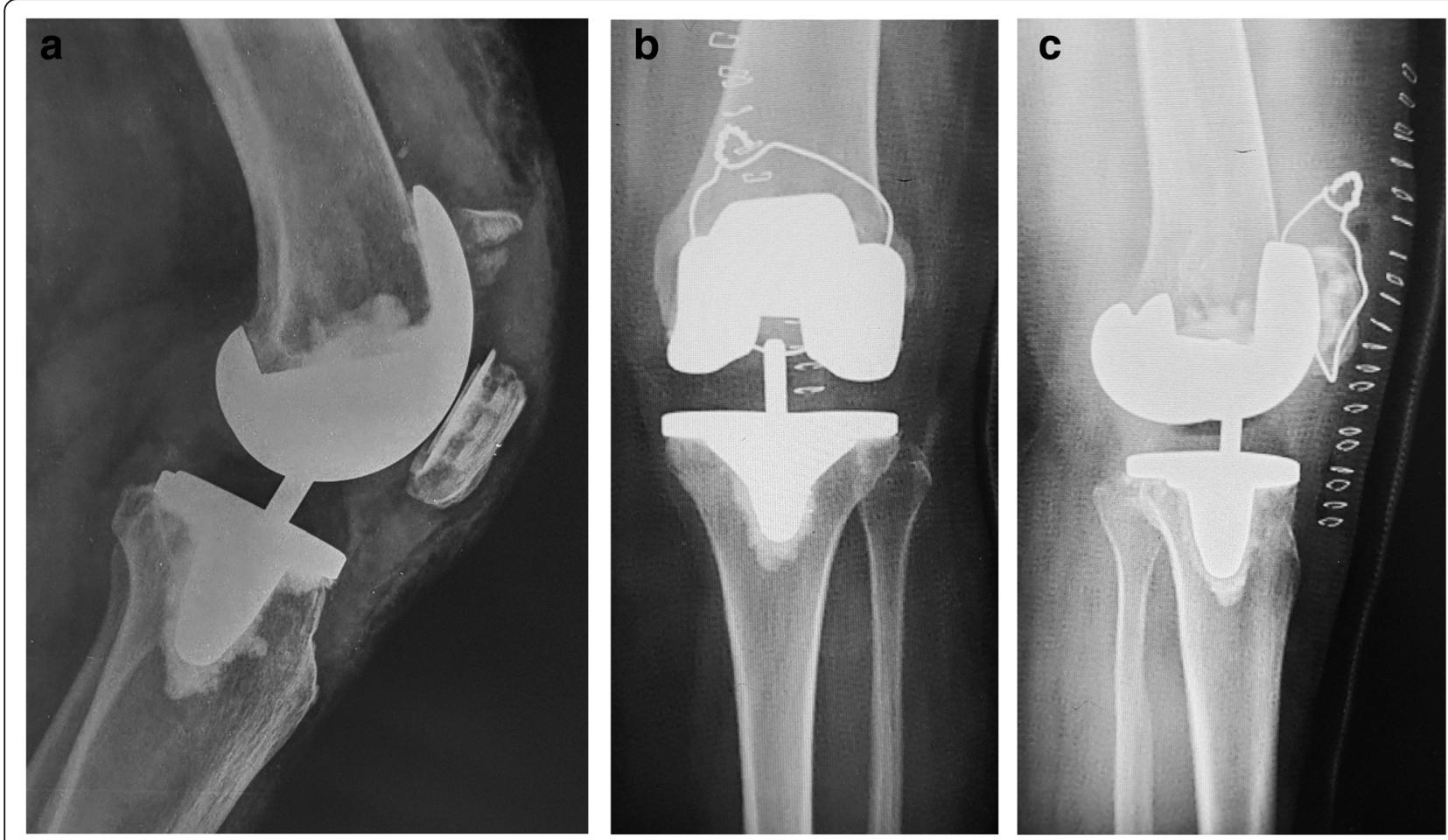

Fig. 1 A 68-year-old female patient who suffered a peri-prosthetic patella fracture (PPPF) in her left knee (case 1 in Table 1). a Preoperative lateral X-ray shows a PPPF with extensor mechanism rupture and rotating hinge knee system (Depuy) with stable patellar implant. b Postoperative anteroposterior view shows the fracture is reduced and fixed with cerclage wiring. $\mathbf{c}$ Lateral X-ray shows good approximation

\section{Risk factors}

The risk factors of PPPFs include advanced age, osteoporosis, over-clamping of the patella during resurfacing, over-reaming of the patella, slippage of the reamer, aggressive patella resection with remaining bone stock less than 10 to $15 \mathrm{~mm}$, thermal injury, bone necrosis due to polymethylmethacrylat cement, and revision of the patellar component particularly in patients with less bone stock [2-4]. Resurfaced patellae are more prone to fracture than their non-resurfaced counterparts [3]. Either under-correction or over-correction should be avoided [11]. A thicker patella may cause the loss of flexion and lateral subluxation, whereas a thinner patella may result in patellar stress fracture and anteroposterior instability of the knee $[4,5,10]$. During lateral release, preserving the lateral vessels, superior lateral genicular artery, and the fat pad can decrease patellar devascularisation [2-4, 10]. Associated medical comorbidities, including rheumatoid arthritis, diabetes mellitus, chronic renal failure, obesity, and hyperthyroidism, may be associated with poor outcomes [1, 4-7].

During the primary TKA, it is important to select a fitting patellar component, correctly position the components, and achieve proper patellar match and tracking. Larger femoral components and mal-positioning of the femoral components in flexed position increase the reaction force of patellofemoral joint, resulting in an elevated risk for PPPFs [9]. Other issues that deserve our attention include: (1) a posterior-stabilized total knee prosthesis had increased contact stress across the femoral component, thereby increasing the patellofemoral contact stresses and the risk of patellar fracture [9]; (2) using a single large central peg component may disrupt the intraosseous vascular supply [4]; (3) revision TKA may be an independent risk factor, which increases possibility of immediate post-operative fractures [1].

\section{Clinical manifestations}

Most PPPFs are asymptomatic, and often have underlying pre-existing factors causing aseptic loosening, infection, arthrofibrosis, and patellofemoral complications $[1-5,9$, $10,12]$. Patients with missed injuries may suffer from instability of the knee joint, followed by the failure of TKA [8]. In patients highly suspected of the injuries, extensor mechanism ruptures and fractures should be ruled out.

\section{Imaging study}

X-ray examination usually suffices to identify PPPFs. A skyline view may be helpful sometimes. However, X-rays may not provide definitive evidence of component stability 

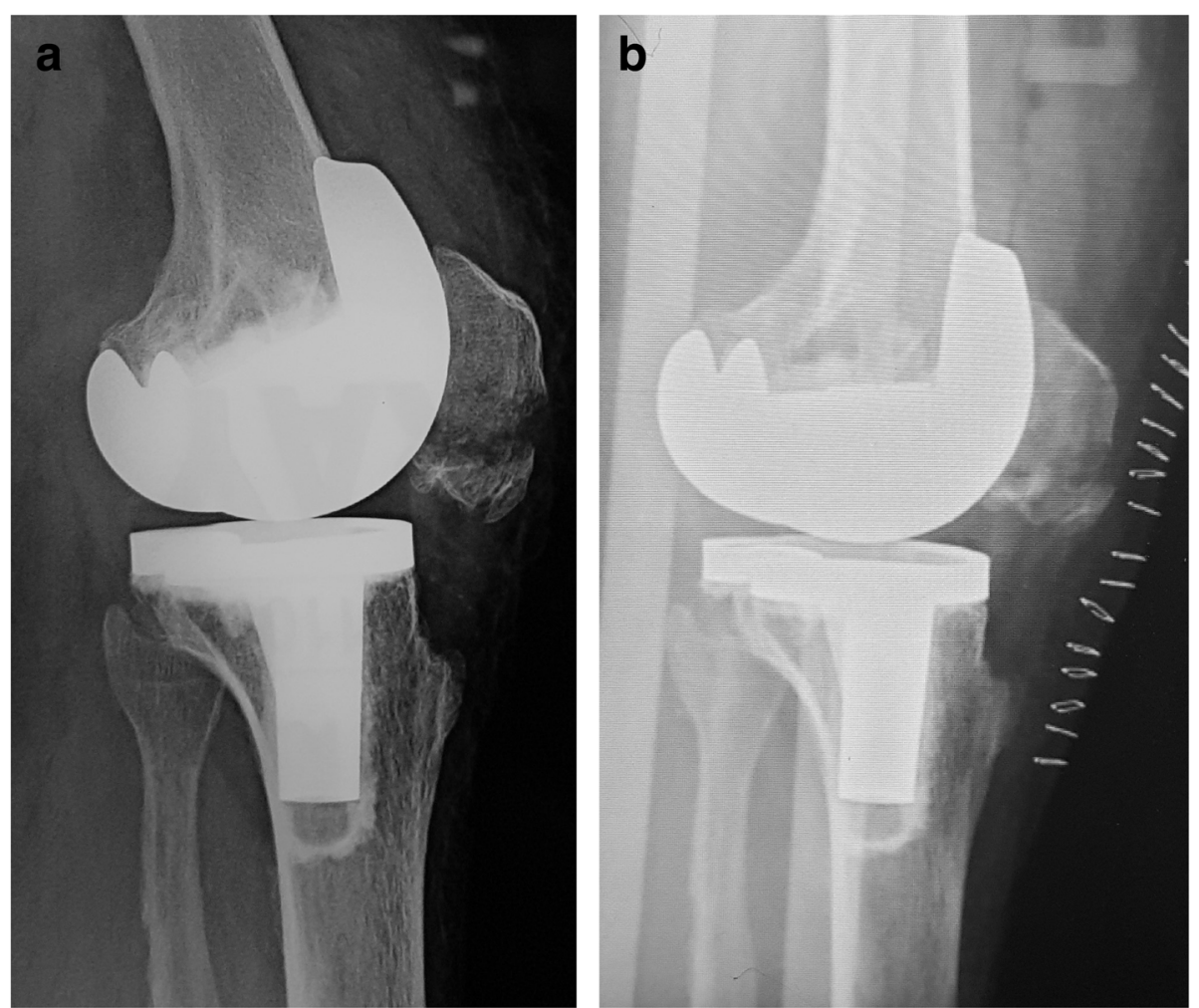

Fig. 2 A 65-year-old female patient who had a PPPF in her right knee (case 2 in Table 1). a Preoperative lateral X-ray shows the displaced and comminuted PPPF with extensor mechanism rupture. b Fixation is achieved with Ethibond polyester suture

[11]. CT scan shows a better fracture geometry [1]. Technetium $\mathrm{TC}^{99 \mathrm{~m}}$ medronate bone scan may be useful in the differentiation between old and new fractures [9].

\section{Treatment selection}

Stable and undisplaced trans-patellar fractures are usually treated conservatively. Unstable and displaced transpatellar fractures may require an internal fixation. If the implant is unstable, a revision surgery is needed $[1,3,4$, 13]. After reviewing 19 studies regarding PPPFs, Chalidis et al [10] found that $67 \%$ of PPPFs were treated nonsurgically. They emphasized that surgical revision is required only if there is an injury to the extensor apparatus or patellar implant loosening [1].

We conducted a review of articles published between 2006 and 2020. We found high failure rates (approximately 92\%) of surgeries for PPPF. Therefore, simple open reduction and internal fixation were not routinely recommended $[2,10]$. Surgical procedures should include restoring continuity of the extensor mechanism by excising small poor-quality osseous fragments, and repairing the remaining extensor tendon $[1,2,11]$. Internal fixation can be achieved using anchor sutures [14], tension wire [15], lag screws with neutralizing plate [16], and locked mesh plates [17]. However, tension-band wiring is desirable for this purpose. Excising the displaced distal pole fragment followed by patellar tendon repair and even patellectomy is indicated if all other treatments fail [12]. Currently, no optimal technique is available for open reduction and internal fixation due to the fact that only limited cases of PPPFs were reported. Usually, superior or inferior pole fractures are treated with tension band technique. If the passive flexion is less than $75^{\circ}$ with tension, augmentation of the extensor mechanism using a semi-tendinosus or iliotibial band tendon autograft, allograft, or xenograft is indicated $[8,9]$.

\section{Expected outcomes}

Good functional outcomes are often achieved in patients without extension lag and with sufficient bone stock [2, 4]. Poor outcomes may be attributed to the coexisting osteoporosis, especially in elderly female patients with combined rheumatoid arthritis. In order to prevent PPPFs, it is important to follow the basic principles of TKA, i.e., achieving the proper extensor mechanism alignment, balancing the soft tissues, and obtaining accurate bone cuts [4, 5, 12, 18]. Type II PPPFs are associated with high rates of complications (50\%) and recurrent surgeries (42\%) after 

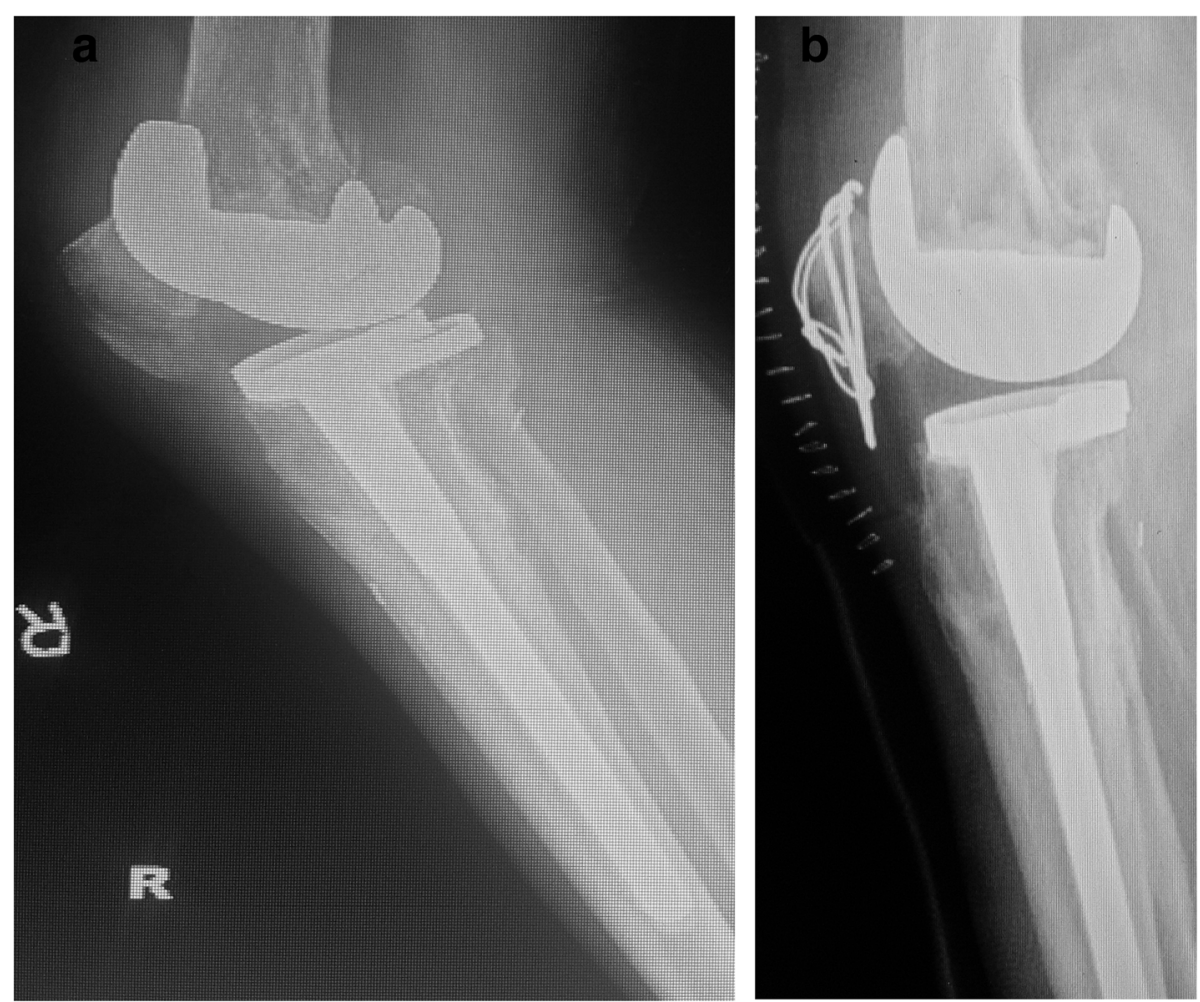

Fig. 3 A 72-year-old women who suffered a PPPF (case 3 in Table 1). a Preoperative lateral view showing a posterior stabilized system (Depuy) with stem extender. $\mathbf{b}$ The displaced inferior pole fracture is fixed with tension band wiring
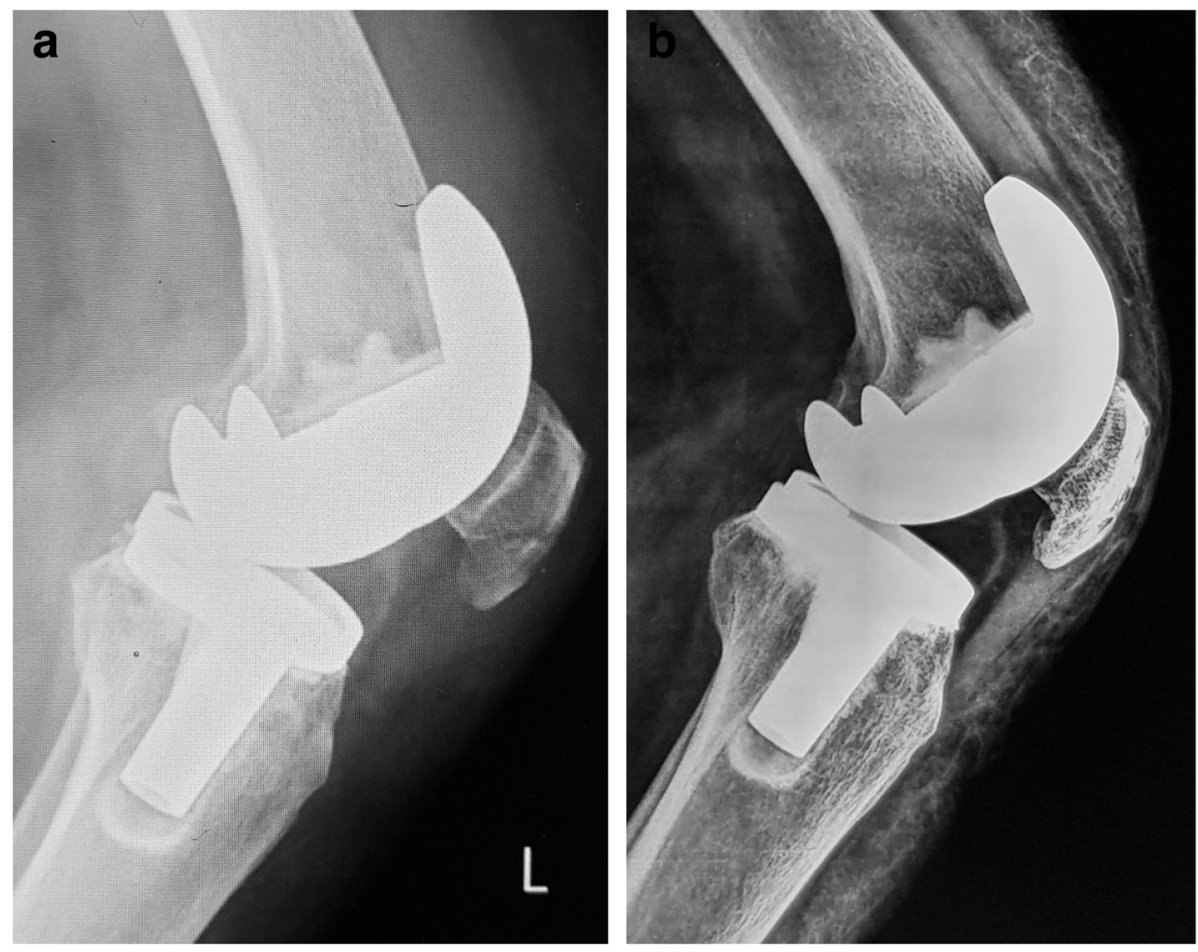

Fig. 4 A 64-year-old female who suffered a PPPF in her left knee (case 4 in Table 1). a Preoperative lateral X-ray shows a posterior stabilized system (Depuy) and minimally displaced fracture. $\mathbf{b}$ The fracture is managed conservatively with good union one year later 
osteosynthesis. Rehabilitation plays an important role in regaining the pre-fracture level of activity. When removing the patella component, leaving an osseous shell may contribute to the development of anterior knee discomfort and crepitus [9]. Generally, extensor mechanism repair often produces poor results.

\section{Limitations}

Our study has some limitations. The study lacks a control group. The sample size of the series was too small and cannot be used to identify the factors for predicting outcomes. The study cannot serve as a fixation guideline for PPPFs. Future studies should be done in larger cohorts, with control groups set.

\section{Conclusion}

Generally, undisplaced PPPFs should be treated nonoperatively whenever possible. For displaced fractures, open reduction and internal fixation and repairing the combined extensor mechanism injury can yield good functional outcomes.

\section{Abbreviations}

PPPF: Periprosthetic patella fracture; TKA: Total knee arthroplasty

\section{Acknowledgements}

Not applicable.

\section{Authors' contributions}

LT, GG and PD conceptualised the study design and collected data for the study. GG prepared the manuscript. The authors read and approved the final manuscript.

\section{Funding}

No funding was received for this study.

\section{Availability of data and materials}

The datasets used and/or analysed during the current study are available from the corresponding author on request.

\section{Ethics approval and consent to participate}

Not required as it was a retrospective case series.

\section{Consent for publication}

Informed consent that data will be used for publication was taken from all patients.

\section{Competing interests}

None of the authors have competing interests to declare.

\section{Author details}

'Department of orthopaedics, Max Super Speciality Hospital, 108 A, I.P. Extension, Patparganj, Delhi 110092, India. ${ }^{2}$ D-101, Sunshine Helios, Sector 78, Noida, Uttar Pradesh 201305, India. ${ }^{3}$ Address: A-702 Vardhman apartment, Mayur Vihar phase1extension, Delhi 110091, India. ${ }^{4}$ Address: House no 37, Sukh Vihar, Delhi 110051, India.

Received: 26 May 2020 Accepted: 4 October 2020

Published online: 04 November 2020

\section{References}

1. Benkovich V, Klassov Y, Mazilis B, Bloom S. Periprosthetic fractures of the knee: a comprehensive review. Eur J Orthop Surg Traumatol. 2020;30:38799. https://doi.org/10.1007/s00590-019-02582-5.
2. Canton G, Ratti C, Fattori R, Hoxhaj B, Murena L. Periprosthetic knee fractures. A review of epidemiology, risk factors, diagnosis, management and outcome. Acta Biomed. 2017;88:118-28. https://doi.org/10.23750/abm. v88i2-S.6522.

3. Chun KA, Ohashi K, Bennett DL, El-Khoury GY. Patellar fractures after total knee replacement. Am J Roentgenol. 2005;185:655-60. https://doi.org/10. 2214/ajr.185.3.01850655.

4. Yoo JD, Kim NK. Periprosthetic fractures following total knee arthroplasty. Knee Surg Relat Res. 2015;27:1-9. https://doi.org/10.5792/ksrr.2015.27.1.1.

5. Parvizi J, Kim Kl, Oliashirazi A, Ong A, Sharkey PF. Periprosthetic patellar fractures. Clin Orthop Relat Res. 2006;446:161-6. https://doi.org/10.1097/01. blo.0000218722.83601.18

6. Ortiguera CJ, Berry DJ. Patellar fracture after total knee arthroplasty. J Bone Joint Surg Am. 2002;84:532-40. https://doi.org/10.2106/00004623200204000-00004

7. Goldberg VM, Figgie HE III, Inglis AE. Patellar fracture type and prognosis in condylar total knee arthroplasty. Clin Orthop Relat Res. 1998;236:115-22.

8. Vaishya R, Agarwal A, Vijay V. Extensor mechanism disruption after total knee arthroplasty: a case series and review of literature. Cureus. 2016:8:479 doi:10.7759.

9. Sheth NP, Pedowitz DI, Lonner JH. Current concepts review-periprosthetic patellar fractures. J Bone Joint Surg Am. 2007:89:2285-96. https://doi.org/10. 2106/JBJS.G.00132

10. Chalidis BE, Tsiridis E, Tragas AA, Stavrou Z, Giannoudis PV. Management of periprosthetic patellar fractures: a systematic review of literature. Injury. 2007;38:714-24.

11. Putman S, Boureau F, Girard J, Migaud H, Pasquier G. Patellar complications after total knee arthroplasty. Orthop Traumatol Surg Res. 2019;105:S43-51. https://doi.org/10.1016/j.otsr.2018.04.028.

12. Sayeed SA, Johnson A, Delanois RE. The treatment of patellar fractures after total knee arthroplasty. Semin Arthroplasty. 2018;21:139-41.

13. Rayan F, Konan S, Haddad FS. A review of periprosthetic fractures around total knee arthroplasties. Curr Orthop. 2008:22:52-61.

14. Maniar RN, Nayak RM, Vatchha S, Singhi T. Periprosthetic patellar fracture fixation using suture anchors. Orthopedics. 2013;36(11). https://doi.org/10. 3928/01477447-20131021-36

15. Masmoudi K, Grissa Y, Benzarti S, Cheikhrouhou H, Mensi Z. Open periprosthetic patellar fracture after total knee replacement. J Orthopaedic Case Rep. 2016;6:89-91. https://doi.org/10.13107/jocr.2250-0685.452.

16. Lindemeier SC, Brazier BG, Ruhland ED, Cochran JM. Treatment of periprosthetic patella fractures using a lag screw and neutralization plate construct: a novel surgical technique. Tech Orthop. 2019;00:000.

17. Siljander M, Gandhi S, Koueiter DM, Wiater PJ. Osteosynthesis of a periprosthetic patella fracture with a locked mesh plate. Int J Orthod. 2017; 28:811-3. https://doi.org/10.17554/j.issn.2311-5106.2017.04.229.

18. Agarwal S, Sharma RK, Jain JK. Periprosthetic fractures after total knee arthroplasty. J Orthop Surg. 2014;22:24-9.

\section{Publisher's Note}

Springer Nature remains neutral with regard to jurisdictional claims in published maps and institutional affiliations.
Ready to submit your research? Choose BMC and benefit from:
- fast, convenient online submission
- thorough peer review by experienced researchers in your field
- rapid publication on acceptance
- support for research data, including large and complex data types
- gold Open Access which fosters wider collaboration and increased citations
- maximum visibility for your research: over $100 \mathrm{M}$ website views per year
At $\mathrm{BMC}$, research is always in progress.
Learn more biomedcentral.com/submission 